\title{
A Rhizo-Poiesis: Children's Play(ing) of Games
}

\author{
MARG SELLERS \\ RMIT University (Australia)
}

What follows is my rhizopoiesis, a conjoining of Trueit's (2006) Play which is more than play and my ideas, nomadically-rhizomatically generating a further disruption of ideas about play as presented in the early childhood literature. My reading-writing-thinking can be perceived, both abstractly and with/in the actual, as a "vertical dimension of intensities" (Foucault, 1977, cited in Hand, 1988, p. xliv). To disrupt a conventional interpretation of Trueit's article, I transpose selections of her rather lyrical text into a poietic format, as a way of opening (her) ideas to a rhizomatic understanding of children's play. Centering the text disturbs any regression into a linearly focussed reading. By virtue of what I have included and what I have left out, the re-presentation inevitably reflects my subjective partiality of my understandings of her text, and associated limitations - "Are we not subject to our own limited "understandings" as we impose our interpretations on others?" (Smitherman Pratt, 2006, p. 91). Another (re)reading on another day and I might change what is/not included-"understanding is always changing, in flux, continually being renewed" (p. 93). This (re)reading/writing is processual; I have no idea before doing it what I might find, what might be revealed, what understandings might emerge. Similar to Richardson (1997), I feel the urge to step aside from the dreary writing of ordinary academic prose; to enact "a threshold occasion: a moment of ecstasis when something moves away from its standing as one thing to become another."1 I thus play with the idea of playing with Trueit's text to see what happens, what spaces of possibilities might open.

\footnotetext{
${ }^{1}$ http://en.wikipedia.org/wiki/Poiesis. See also, Threadgold (1997).
} 


\section{Mythopoesis of play}

\section{Play-fully engaging with Donna \\ Trueit's (2006) writing about \\ Play Which Is More Than Play, in which I is Donna}

\author{
Much has been written about play \\ from various disciplinary perspectives, \\ about the value of play, \\ its relationship to child development \\ and to learning.
}

We all know "play" don't we?

Why search for new meanings?

\footnotetext{
I [Donna] hope not only to open up modernist habits of thought, but also to suggest that play might be the organizing principle of a discursive practice.
}

An overview of understandings of play illuminates various work(ing)s of the concept of play. In these, developmental approaches are mediated by sociocultural critiques, but modernist thinking pervades.

The assumption that everyone knows about play is foregrounded here by Trueit's facetious question, to which I respond in kind: Of course we all do/n't know about play. Trueit's question points to the tendency to trivialise "play". Play goes hand-in-hand with (western) conceptions of childhood and as all adults have passed through (graduated from?) childhood, what more is there to know or be said about it? We played. Play happened. So what? Subjectively affected by my childhood experiences of play, I bring my scholarly understandings in to the play of play-fully responding to this question. In working (with/through) this mythopoesis, I am alert for re-newed ways of re-thinking play.

Like Trueit, I want to disrupt the modernist agenda that pervades and suggest how we might re-think "play". For the moment, I transpose (again) her ideas, this time from poem into scholarly discourses. In the poem, I map Trueit's ideas; now, in this juxtaposition, I plug the 
Note: Discursive practices shape, and are shaped by thought.

As the organizing principle of mythopoetic (primarily oral) discursive practices, one that has far greater complexity than the modernist practices of representation that continue to hold us captive. tracing back into the map in a (re)shaping of my thinking; in (re)thinking the poetical (re)reading of her text.

I consult the OED for a definition of mythopoetic and find it used in reference to Māori: 1. = MYTHOPOEIC adj. 1914 Jrnl. Royal Anthropol. Inst. 44139 It is clear that the ancestors of the Maori, in common with other races, strove to fathom the unfathomable... The above is part of the result, ideas evolved by a mythopoetic people.

Striving to fathom the unfathomable - not least in navigating to Aotearoa $\mathrm{New}$ Zealand, talking ideas into be(com)ing through storytelling or becoming-myth. What am $I$ attempting here in a mythopoetic gesture?

I engage with Trueit's projected flow of movement through play - read play ambiguously here, as performance and as constantly changing movement-with recursivity, interrelating systems, speed and flow, thresholds of in-betweenness, openings. Complex, yes, and hard to shake off modernist trappings of representation-language, discourses and the notion of representation itself. Biesta and Osberg (2007) outline complexity's challenge to representation: a static, passive, or representational view of knowledge relies on a binary understanding, "which holds that the world is simply present in and of itself and that we can acquire knowledge of it ... [a] binary logic of representational epistemology ... that there is a real world that knowledge somehow reflects" (p. 24); "that knowledge is an accurate representation of something that is separate from knowledge itself (Osberg, 
In modernist discursive practices one observes play, objectifies play as a "thing" or an "event," and represents "play" definitely. However, modernist discursive practices are

(1) very different than the dominant discursive practices that preceded them; and

(2) these prior practices probably cannot be fully appreciated from our now too distant stance. [But,]

we can speculate - and it is necessary for us to do so, because in regard to "methods of representation and the recasting of meaning" there have been "universes of thought evolving into other universes of thought."

Due to the recasting of meaning, I am led to consider the implications of another meaning of play as "the play," as in theatrical performance, as an acted re-presentation of a story. I speculate that the play is not the thing itself, but rather,

the play is a site of far greater complexity,
Biesta \& Cilliers, 2008, p. 213). Rather, knowledge and reality "are part of the same emerging complex system which is never fully "present" in any (discrete) moment in time" (p. 213). These authors call this "emergence". Emergence explicates active and adaptive understandings "towards questions about engagement and response" (p. 213), releasing us from modernist captivity.

In reviewing the concept of play, I note that pervasive modernist practices linger. "Play" is under scrutiny as Ailwood's (2003) analysis disrupts long held relatively simplistic and naïve understandings, bringing other agenda out of the shadows. But, play is still objectified as something that happens, as an experiential event and an eventful experience, albeit with poststructuralist leanings. Alternatively, Trueit's engagement with cosmological ideas that precede modernism, although distant and speculative, opens an oscillation through past $\sim$ present $\sim$ future space-times or universes of thought. A change from always thinking forward in relation to the not-so-distant past; a change thinking differently? Beyond representation; thinking emergence?

Epistemology addressed, play(ing) with play(ing) becomes the conversation and a linkage appears to children playing their imaginary games (i.e. of play) and the games they play (i.e. "the play"), particularly those informed by children's literature, the media and popular culture. So the game is not perceived as the thing itself but as a site of complexity, a milieu of various becomings, spaces of convergence and (con)fusion. As children and games 
a nexus, or perhaps, a temenos, in Ancient Greek thought "a sacred space within which special rules apply and in which extraordinary events are free to occur."

The play is not just the play: it is much more.

And it is the "more-ness" in this sacred space of play

I wish to bring forward:

the staging of cultural education (paedeia)

leading to creativity and transformation. In this place, in this ancient time, the play was not just entertainment it was education; recreation was for re-creation. converge, adults may see only confusion among/within children's games (in early childhood settings). Yet, the temenos or space-time of early childhood requires educationists' respect for the children and their understandings played out in their games. Along with the children, we must expect the unexpected and accept the surprise of its occurrence within this playsite of complexity.

So...the play is not just the play; the play is not just the game; the game is not just the play; the game is not just the game. "Moreness" or "and... and...and..." (Deleuze \& Guattari, 1987, p. 25) is foregrounded within the paedeia of the setting. This OED quotation elaborates paedeia:

1904 S. H. BUTCHER Harvard Lect. on Greek Subj. ii. 124 The Greek Paideia (ПAI $\triangle \mathrm{EIA}$ ) in its full sense involves the union of intellectual and moral qualities. It is on the one hand mental illumination, an enlarged outlook on life; but it also implies a refinement and delicacy of feeling, a deepening of the sympathetic emotions, a scorn of what is self-seeking, ignoble, dishonourable - a scorn bred of loving familiarity with poets and philosophers, with all that is fortifying in thought or elevating in imagination.

The creativity and alterity characteristic of milieu(s) of children's games emerge through/with such understandings of the complexity of the culture of the setting and through/with the cultural complexity of the setting. Becoming- is apparent in the re-creation that happens through the game and its play(ing). Entertainment and education; play and learning are mutually constitutive and their conjunction alters both (De Castell \& Jenson, 2003). 
In this sacred space of play extraordinary events occur.

Energy flows through all things, bringing contiguity.

The free play of forces brings in to relations:

players [the children]; time

[of past, present and future relationships and games (to be) played];

senses: speaking, hearing, seeing, feeling;

and inter-subjectivities

[fairytale and popular culture heroes and heroines].
There is a flowing together

that forms an unbroken sequence in time

and uninterrupted expanse in space.

There is a dynamic system of patterns and transformation

that "makes it possible to deal with
Yet, how extraordinary is this, really, considering the complexity of this playsite? And, considering the chaos of energy, forces, players, time, senses, intersubjectivities? Toscano (2005) explains chaos in Deleuzian understandings as infinite speed of forms and entities emerging and disappearing simultaneously leaving no points of reference. So, as energy ebbs and flows through both children and their games, borders are crossed over and crossed out and the free play of forces, the play or movement of what happens between forces, becomes an(other) entity. Children as players within games merge within relationships among each other: as they relate to each other and brush alongside others relationships with others; remembering past relationships and present affects, experiencing relationships of the now, envisaging relationships as they may be in the future. And, into the chaos of in-between spaces come memories of games already played; as well, energy of present games and expectations of what these games may/will become. The children bring their senses into play as they negotiate relationships and the storyline of their game drawing characters in and drawing from the characters as they are played.

Children within games flow together, sometimes together and sometimes multidirectionally. The storyline may not emerge as expected by any/all of the players and in that sense it is disrupted. In another sense, as long as the game continues it is unbroken. But, even if/when time intervenes (e.g. tidy-up time or home time), the games most often only pause, to be taken up again at the next session 
unresolvable differences and contradictions"

in a relational manner.

\section{Recognizing patterns and rhythms. \\ Recognition by "patterns of resemblances" \\ means that of bundles of relations must be seen \\ rather than one set of relations, or isolated events. \\ While all situations are contextual, one is, \\ in a mythopoetic culture, looking at an event as a bundle of relations over time.}

This backwards and forward looking marks the threshold of play, for in this culture, the play, as a sacred temenos

where extraordinary events are free to occur, insists on the flow of dynamical interactions.

The dynamic flow of play is complicated, but the energy might be thought of deriving from the use of language (which is why I suggest play is the organizing principle of mythopoetic discursive practices). or soon after. Even when the play-space is interrupted, the game is likely to re-emerge in another play-space in a similar or altered form. Patterns and rhythms of play within games and of games seem tacitly understood by the players. With practice, through generating the data and working with it, these become recognisable to me. I see that play is a heterogeneous bundle of relations, ideas and understandings that have "merged and collided over time" (Ailwood, 2003, p. 295), all in oscillation.

In the oscillation, the constant moving backwards and forwards through the storyline of the game now and reflections of similar or different storylines already played, thresholds are glimpsed in stopstart moments as games and players turn ebbs into flows. Or is it more of a fibrillation, a quivering of uncoordinated movement(s)? In liminal spaces of the games and their playing, interactive flows (e)merge.

Play and its playing are complex, yet its energy is illuminated in the children's talking their way through storylines. Play, I suggest, is also a methodology, a way of children expressing complex understandings and a way of opening those understandings to adults. But, immediately I think of cultural lore: Inasmuch as (western) anthropology may want to understand the lore of ether cultures, why does it assume that other/ed cultures might want to share their understandings? Similarly, just because adults want to know, doesn't necessarily mean children want to tell. But, we can be(come) with them in their curricular 
The audience members are drawn out of themselves, their energy flowing outward, toward the events enacted on stage, reacting to the performance; and energy from the performer is absorbed, drawn into,

as the viewer receives this version of the tale.

This active engagement and participation, giving and receiving, attention and reflection, is part of paideia, being drawn into oneself, drawn continuously forward. Each performer and participating viewer

allows him or herself to be drawn in to the movement and find the play, the slip, in a situation, to be in the movement, and to work with spaces. Perhaps we need to (re)learn to play, ourselves and with them. If we want children to work alongside us towards shared understandings, why not learn to play alongside/with children; "with" as engaging in their play-full activity, not "with" as in toy. For the moment, in this moment, my suggestion is that we (re)learn play(ing).

So, adult-outsiders become part of the audience but must be willing to be drawn into the play and the game, towards the players, responding to the playing. We see other parts of the audience playing their part, players of bordering games becoming part of the energy as the games brush alongside each other, merge and collide, responding to the performance of players of other games. The energy melds; energy of the game and its players and energy of outsiders and the exteriority of the milieu. Each understands the game in their way.

Players interact with the exteriority, aspiring singularly and severally to the multiplicity of the paedeia, players oscillating between inside and outside, so the inside becomes the outside, insider becomes outsider, inside(r)-outside(r). Drawn into the movement or the machinic play of the play, into the liminality of play's constant motion.

Play(ing) with/in the slip. Here the storyline (e)merges, in response to what has already happened, responding to creations of the players, to players' creativity. And, I am glimpsing an emerging storyline around "play". 
the movement,

to find-to create-variations.

But there are multiple sites of play in the play,

and the flow of reflexivity and reflection infuses all,

permeating individuals with cultural values of creating, perhaps even creating as an ethical responsibility creating self.

Self in this sense is not an object, but rather seems almost another site of play, of reflexivity, reflection and connection,

with the other and with tradition.

Gadamer (1998, pp. 103-109) associates play with performance and the dynamism of play with creating self. He says:

The movement of playing has no goal that brings it to an end;

rather, it renews itself in constant repetition.

The movement backward and forward

is obviously so central to play that it makes no difference

who or what performs this movement.

The player is subsumed by the play, playing without purpose or effort, absorbed into the structure of play, and relaxed by it.

First and foremost play is selfrepresentation. All presentation
In the multiplicity of the milieu, of playing in the games, of the games in play, the children collectively and collaboratively negotiate their storyline(s), in an ethics of processing through their own becoming, and merging and colliding with others in their becoming. Becoming child/ren emerging.

Not being a particular someone. $\mathrm{Be}(\mathrm{com})$ ing someone different. Becomingchild, singularly and severally. Becomingchildren, different, yet understandable within the lore of the paedeia.

Moving through, moving with, moving in games-playing-becoming-child/ren.

The games are never-ending. They pause only as children tire of negotiating storylines or when the programme says it's time for something else. Like a rhizome, they shoot in (an)other moment(s), later, tomorrow, next week. Games keep going, newly different in different moments. For the game to continue, characters and roles shift within moments of movement, within movement of moments. What matters is that the game continues. The game takes over, draws the players in, with no end other than the processual condition. Process is (Means and end).

Play is about becoming-, in whatever way matters. The gaming (presentation) is about always already becoming-. Within the space-time of the setting and programme, insider-outsider becomes the storyline. 
is potentially a representation for someone.

Play before an audience becomes the play and

openness toward the spectator is part of the closedness of the play.

The audience only completes what the play as such is:

a process that takes place "in between."

Play does not have its being in the player's consciousness or attitude, but on the contrary play draws her/him into its dominion

and fills her/him with its spirit.

The player experiences

the game as a reality that surpasses her/him

all the more the case where the game is itself "intended" as such a reality-for instance, the play which appears as presentation for an audience.

Each performative occasion is an opportunity to create,

to reinterpret and to grow through the experience.

The extraordinary occurrence of play, the "more-ness,"

derives from the powerful dynamism of relations and interactions, the circumstances for the emergence of the new and for transformation.

This semantic play does not provide a neologism for play, a word-like "spirit" - that defies
Openness and closed-ness in never ending de-territorialising movement, deterritorialising play (verb/noun), de-territorialising play (adjective/noun), interrelations among insider-outsider players contesting the game and the storyline processing in the in-between; also, read "play" ambiguously as what children do and machinic movement.

The players become the game, both develop into and are accepted as the game and enhance the game.

The game and its storyline become more than the collective contributions of the players.

It becomes a milieu, an "interior milieu of impulses and exterior milieu of circumstances" (Deleuze \& Guattari, 1987, p. 317).

Becoming-(...), becoming...

There is no playing down the complexity of play, of play as movement. Elusive, indefinable, dynamically changing, emerging.

However, these semantics have not overwritten or over-played play with any newly coined expression. "Play" and play(ing) fly free, avoiding concretising. But, I do have an offering as to how might we conceive of play differently. It is about finding a way beyond thinking of play as 


defining.
It presents only a speculative re-
description
of play as dynamic flow
through which systems-cosmological,
mythological, human, and natural-
are transgressed,
transcended,
and transformed.

Play, as the organizing principle of discursive practices

or re-presentation (re-enactment) in

Ancient Greece,

blows open

the tight

and constraining

discursive practices of representation in modernity.

But then, we all know about "play," don't we? thing or event and thinking of play verbally, as dynamism and movement, as a milieu of becoming. "Becoming is the pure movement evident in changes between particular events... [It is] a characteristic of the very production of events. It is not that the time of change exists between one event and another, but that every event is but a unique instant of production in a continual flow of changes evident in the cosmos. The only thing "shared" by events is their having become different in the course of their production" (Stagoll, 2005, pp. 21-22, original italics).

Following Trueit's playing mythopoetically with play, I would approach the discourses of play (in the early childhood literature) play-fully. I would blow open the modernist representation of the centrality of play to supposed developmentalist advantage. I would work to disrupt thinking that enables play to be understood as governmentality, and more. I would present a rhizopoietic offering of play as a machinic assemblage, a milieu of becoming (Deleuze \& Guattari, 1987).

And, I would not pretend to know anything about "play" as children understand it until I (re)learn to be a player as children are in their childhoods, until I (re)learn to play as children do. Sutton-Smith (1997) says: "We all play occasionally, and we all know what playing feels like" (p. 1). But, do we? It is like drawing and painting; when we stop doing it, we forget, we stop learning how to do it. When we stop playing, we stop learning about it or how to do it; we stop learning what play(ing) is, what play(ing) means; we stop understanding play(ing). 
In play-fully engaging rhizopoietically with play which is more than play, I hope this (ad)venture has gone some way towards disrupting the idealisation of children's play that pervades much of the work of play theory and interrupted order and rationality in favour of a Dionysian approach relating to the sensual, spontaneous and emotional. Hopefully, I have also averted a modernist, civilising tendency "to take away play's muddy complexity and reduce it to some kind of pure fun, pure intrinsic motivation, pure flow, rid of all encumbrances" (Sutton-Smith \& Magee, 1989, p. 54) and also turned away from ways of controlling it-both children's play(ing) and theorising about it.

\section{References}

Ailwood, J. 2003. Governing early childhood education through play. Contemporary Issues in Early Childhood, 4(3): 286-299.

Biesta, Gert J. J., \& Osberg, Deborah. 2007. Beyond re/presentation: A case for updating the epistemology of schooling. Interchange, 38(1): 15-29.

De Castell, Suzanne, \& Jenson, Jennifer 2003. Serious play: Curriculum for a post-talk era. Journal of the Canadian Association for Curriculum Studies, 1(1): 47-52.

De Castell, Suzanne, \& Jenson, Jennifer. 2003. OP-ED 'Serious play'. Journal of Curriculum Studies, 35(6): 649-665.

De Castell, Suzanne, \& Jenson, Jennifer. 2003. Serious play: Curriculum for a post-talk era. Journal of the Canadian Association for Curriculum Studies, 1(1): 47-52.

Deleuze, Gilles, \& Guattari, Félix. 1987. A thousand plateaus: Capitalism and schizophrenia (B. Massumi, Trans.). Minneapolis: University of Minnesota Press.

Hand, Seán. 1988. Translating theory, or the difference between Deleuze and Foucault [Translator's introduction] (S. Hand, Trans.). In G. Deleuze (Ed.), Foucault (pp. xli-xliv). Minneapolis, MN.: University of Minnesota Press.

Osberg, Deborah, Biesta, Gert J. J., \& Cilliers, Paul. 2008. From representation to emergence: Complexity's challenge to the epistemology of schooling. Educational Philosophy and Theory, 40(1): 213-227.

Richardson, Laurel. 1997. Fields of play: Constructing an academic life. New Brunswick, NJ.: Rutgers University Press.

Smitherman Pratt, Sarah. 2006. Playing with our understandings. Complicity: An International Journal of Complexity and Education, 3(1): 91-95.

Stagoll, Cliff. 2005. Becoming. In A. Parr (Ed.), The Deleuze dictionary (pp. 21-22). Edinburgh: Edinburgh University Press.

Sutton-Smith, Brian, \& Magee, May Ann. 1989. Reversible childhood. Play and Culture, 2, 52-63.

Threadgold, Terry. 1997. Feminist poetics: Poiesis, performance, histories. London \& New York: Routledge.

Toscano, Alberto. 2005. Chaos. In A. Parr (Ed.), The Deleuze dictionary (pp. 43-44). Edinburgh: Edinburgh University Press.

\footnotetext{
About the author

Marg Sellers has recently submitted a PhD thesis, which brings Deleuzo-Guattarian approaches to rethinking early childhood curriculum and its inquiries. Following early childhood teacher educator and programme leader roles in Aotearoa New Zealand, Marg has recently taken up a lecturing position at RMIT University in Melbourne, Australia.
} 
(C) Copyright 2009. The author, MARG SELLARS, assigns to the University of Alberta and other educational and non-profit institutions a non-exclusive license to use this document for personal use and in courses of instruction provided that the article is used in full and this copyright statement is reproduced. The author also grants a non-exclusive license to the University of Alberta to publish this document in full on the World Wide Web, and for the document to be published on mirrors on the World Wide Web. Any other usage is prohibited without the express permission of the author. 